\title{
Primicias de la atención quirúrgica de los niños mexicanos en el siglo XIX
}

\author{
Firsts surgical care of Mexican children in the nineteenth century
}

\section{Manuel Antonio Baeza-Bacab*}

Unidad Interinstitucional de Investigación Clínica y Epidemiológica, Facultad de Medicina, Universidad Autónoma de Yucatán, Mérida, Yucatán, México

\section{Resumen}

Se presentan dos trabajos que constituyen los primeros informes de procedimientos quirúrgicos en niños mexicanos en el siglo XIX. Las dos publicaciones se refieren a operaciones para la extracción de cálculos vesicales. En ese tiempo no existía anestesia, por lo que parte de la descripción incluye el sufrimiento de los pacientes y las dificultades operatorias. El primer caso está referido como una litotomía en una joven de 17 años, operada por el cirujano José Victoriano Guerrero en Guadalajara en 1822. La publicación no constituye un informe académico, sino un folleto escrito como un obsequio para el emperador Agustín I para celebrar su ascensión al trono. El segundo trabajo es una talla lateral en un niño de 5 años edad, publicado por el doctor Luis Jecker en el primer número del Periódico de la Academia de Medicina de Mégico en 1836.

PALABRAS CLAVE: Cistostomía. Historia siglo XIX. Cálculo vesical. Niños. México.

\begin{abstract}
Here, two papers are presented, which constitute the first reports of surgical procedures in Mexican children performed at the $19^{\text {th }}$ century. The two publications refer to surgical operations for the extraction of bladder stones. At that time, there was no anesthesia, so part of the description alludes to the suffering of the patients and the operative difficulties. The first case, is referred to as a lithotomy in a 17-year-old girl, performed by surgeon José Victoriano Guerrero in Guadalajara in 1822. publication is not an academic report, but a pamphlet written as a gift to Emperor Augustin I to celebrate his ascension to the throne. The second work, is a lateral lithotomy in a 5-year-old boy, published by Dr. Luis Jecker in the first issue of the Periódico de la Academia de Medicina de Mégico in 1836.
\end{abstract}

KEY WORDS: Cystostomy. $19^{\text {th }}$ century history. Calculi of urinary bladder. Children. México.

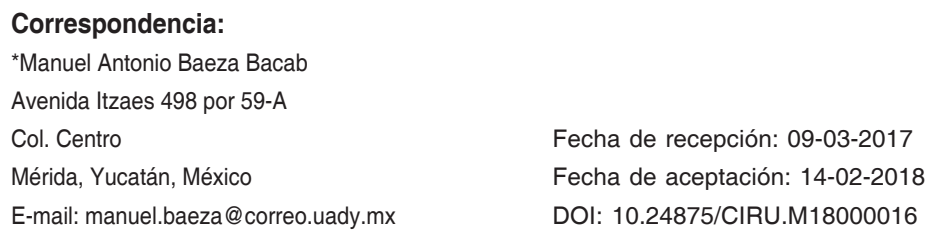

Fecha de recepción: 09-03-2017

Fecha de aceptación: 14-02-2018 DOI: 10.24875/CIRU.M18000016

Cir Cir. 2018;86:108-116

Disponible en PubMed www.cirugiaycirujanos.com 


\section{Introducción}

Antes del siglo XIX, las publicaciones acerca de procedimientos quirúrgicos en los niños eran anecdóticas. De ellas sobresalen una supuesta extracción de un cálculo vesical observada por Cristóbal Méndez alrededor de $1529^{1}$ y la atención que ofreció Pedro Arias de Benavides a un niño con un traumatismo craneano en $1561^{2}$. Al parecer, después de estas citas no hay reportes de otros procedimientos hasta mediados del siglo decimonónico, a partir de lo cual se multiplican los informes, probablemente por el desarrollo de la anestesia y de la antisepsia ${ }^{3}$.

En el primer caso mencionado, existe controversia sobre si fue una litotomía o una autopsia, debido al empleo de la palabra «abrir». En el Libro del ejercicio corporal y de sus provechos (Fig. 1), escrito en 1553, Cristóbal Méndez menciona lo siguiente: «yo vide en México abrir a un niño, hijo de un muy honrado hombre que se dezía Villaseñor, y no había cinco años, y le sacaron una piedra casi del tamaño de un huevo; y sin duda, según su cantidad, que se le hizo antes que naciese $"$. Lo anterior ha sido interpretado en algunos trabajos como un procedimiento quirúrgico. Sin embargo, en la edición crítica del libro, publicada por la Universidad de León, Eduardo Álvarez del Palacio afirma que no se trató de un procedimiento de este tipo sino de una autopsia, ya que la frase del autor: "yo vide en México abrir a un niño...", analizada en su sintaxis y forma expresiva de la época en que fue escrita, no se refiere, según la terminología renacentista, a una operación, sino a un caso de necropsia. El término «abrir», en su acepción quirúrgica, es mucho más moderno, mientras que en tiempos medievales iba siempre unido al vocablo "cadáver», lo que identifica y simplifica el término reduciéndolo a la apertura como sinónimo de autopsia. Por ello concluye que lo observado por Cristóbal Méndez en ese niño mexicano, «hijo de un muy honrado hombre que se dezía Villaseñor», no fue un acto quirúrgico, sino la triste confirmación o descubrimiento de un diagnóstico de litiasis infantil por medio de una autopsia4.

Por otro lado, el trabajo de Pedro Arias de Benavides está considerado como la primera publicación de un procedimiento neuroquirúrgico en América del Norte $^{5}$. Arias fue un cirujano español que ejerció en México a mediados del siglo XVI, y al regresar a España escribió el libro Secretos de Chirurgia (Fig. 2), en el cual relata que, durante su estancia

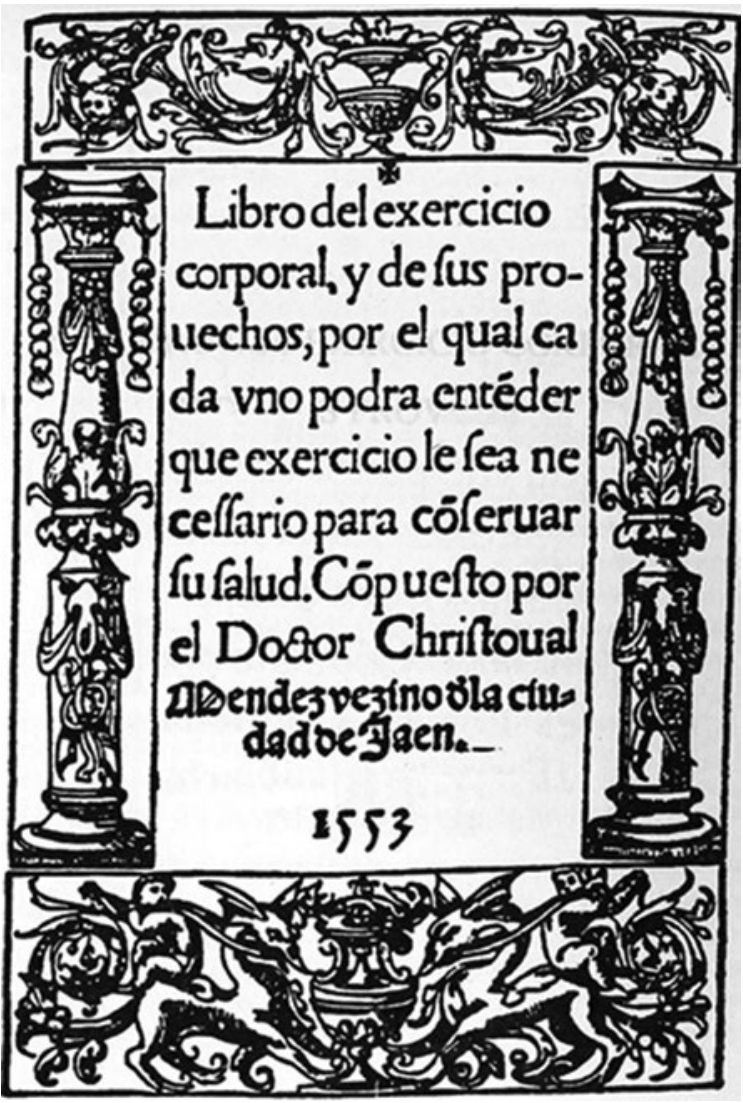

Figura 1. Portada de Libro del ejercicio corporal y de sus provechos, de Cristóbal Méndez, 1553.

en la ciudad de México en 1561, atendió a un mozo de 13 años, llamado Vergara, quien se había caído de un coro de iglesia y fue alcanzado por una cureña (armazón de madera sobre el que se montaba un cañón de artillería) en la cabeza. Arias fue llamado para atenderlo cuando aún estaba sin sentido, haciendo la cura de urgencia; a la segunda curación llamaron a otro cirujano y a un médico, quienes se limitaron a aplicar aceites y digestivos en la herida. Al día siguiente, cuando dejó de sangrar, comenzó a sacar fragmentos de hueso, y al tercer día retiró más huesos y un pedazo de bonete (madera) del tamaño de media haba en la que había pegada sustancia medular en una cantidad equivalente a medio garbanzo. El médico y el cirujano vieron la substancia cerebral y no quisieron volver a la curación, y como él había sido el primero en atender al herido, tuvo que hacerse cargo de la curación de la mejor manera posible, por lo que ordenó un emplasto a base de malvas trituradas (probablemente Malva silvestris $L$., una planta con propiedades emolientes y antiinflamatorias), harina de habas, linaza, alholvas (posiblemente Trigonella foenum-graecum $L$, planta medicinal con propiedades emolientes), 
puede considerar el contenido de la adjunta memoria que sobre ser muy raro ha dado la vida a una infeliz, y la volverá a quienes se hallen en su estado. El amor y la gratitud que profesan los americanos a su libertador, eran motivos más que bastantes, para tributar a V. M. I. lo que su corazón humano, y un entendimiento bien formado, deben recibir, con todo agrado, pero hay más; cuando impelido de solo esos sentimientos iba a ofrecerla a V. M. otro objeto se ha presentado en que también quisiera mostrar mi reconocimiento. La augusta proclamación de V. M. que se ha solemnizado por esta capital el día de hoy es nueva causa para que lo verificara. Yo la dedico pues, mas por significar cuanto sea en mí el afecto y reconocimiento que tan justamente se le deben, que no por creerla suficiente para llenar la grandeza de su fin. Dígnese V. M. I. admitir este obsequio, y qué esa concreción sea una de las cosas que condecoren el gabinete de historia del primer Emperador de Méjico [sic].

Señor.

José Victoriano Guerrero.

Después de la dedicatoria, se describe la evolución de la paciente y la descripción del procedimiento quirúrgico, los cuales se transcriben a continuación:

Hace dos años que se me presentó una joven de diez y siete años, con la menstruación suprimida*, la cual no corrió más del primer año con escases. El color pálido y la languidez de la paciente me persuadieron que la supresión estaba sostenida por un vicio clorótico: recurrí a los tónicos y la previne los mejores alimentos posibles a su pobreza; mas como sus fuerzas se debilitaban, a pesar del método que había emprendido, conocí no ser la causa principal la anunciada, y tomé nueva indicación, y entonces me descubrió que desde la edad de cuatro años padecía disuria (evacuación de orina con dificultad y dolor) y por habérsele dicho que era vicio sifilítico (mal venéreo o gálico) había temido manifestarlo desde antes: suspendí el método anterior, y la puse a el uso de los demulcentes y baños tibios, y en efecto a este plan de curación debió algunos intervalos de alivio.

Sin embargo, de que, con este régimen, a la paciente parecía que los síntomas eran menos graves, viendo que era muy poco lo que se avanzaba, la reconocí con una sonda y me encontré con un cálculo en la vegiga [sic], y aunque solo pude tocar la porción que engastaba el cuello, me persuadí que, para lograr

\footnotetext{
* María Magdalena Madera, hija legítima de Julián Madera y de María Josefa Salas, vive en Guadalajara en el barrio de las flores.
}

una curación radical, era necesaria la operación de la litotomía; se lo propuse así a la paciente, la que mejor quiso seguir padeciendo que sujetarse a ella. Le receté una onza de carbonato de sosa, en cuarenta y ocho papeles para que tomara uno por mañana y tarde en un cocimiento saturado de linaza, encargándole me diera aviso de cualesquiera ocurrencia.

Pasado algún tiempo, cuando la creía sin vida, se me presentó por ser muchas las dolencias que sentía, y hallarse aún más estorbada para andar, diciendo al mismo tiempo que por agravarse cada vez más con los papeles de carbonate, había suspendido su uso: la hice nuevo reconocimiento, y hallé el cuerpo extraño más inmediato, la orina en estado de estranguria (goteando) y las ninfas extremadamente prolongadas é infiltradas, y no siendo posible poderla persuadir a que continuara con el carbonate, me valí del ardid de combinárselo con carbón, y que lo tomara en cuatro onzas de mucilago arábigo por mañana y tarde; con la continuación de esta medicina los síntomas se aumentaban, las extremidades inferiores se infiltraron, $y$ las orinas se escasearon; pero el cálculo avanzaba: dispuse que después de frotarle las piernas con un cepillo, se le dieran fricciones con la tintura de mostaza y láudano líquido, además un jeringatorio de mucilago de linaza y opio, que continuándolo por algunos días, mitigaron algún tanto los dolores, pero las orinas siguieron escasas, y los edemas en aumento; por lo que solo dejé la medicina interna anterior, agregando el cocimiento de rubia de tintoreros por uso, y aumentado la dosis del carbonate a una dragma [sic] por día en cuatro papeles. A este tiempo los dolores eran tremendos, así como los conatos expulsivos: la reconocí por tercera vez y siempre me figuré indispensable la operación, aunque no tan complicada: se lo manifesté así a la enferma, persuadiéndola lo mejor que pude y diciéndola, con el fin de animarla, que, de no allanarse a ello, me retiraría para no volver, y solo me respondió, suplicándome esperara algunos días, y que de no aliviarse pasarla por la propuesta operación. Después de haberle señalado el plan de curación que debía seguir, la visité cuatro días en los que no tuve que alterar porque la encontré en el mismo estado: el quinto día no la visité, el sexto me solicitó la madre, y me hizo ver que estaba en un estado fatal, me fui para la casa y la encontré en una situación tan deplorable, que sus lamentos, los extraordinarios e inútiles esfuerzos que hacía para arrojar el cuerpo extraño, y las enternecedoras súplicas para que se le quitara aquel tormento, me compadecieron hasta el punto que jamás desgracia alguna ha conmovido en 
semejante manera mi corazón. No quise perder la ocasión oportuna que se me presentaba para poner en práctica el remedio que me parecía conveniente: la reconocí con más exactitud, encontré que el cálculo había vencido al cuello de la vegiga y próstata [sic], que esto era un auxilio que facilitaría más la operación, y que últimamente era de necesidad, porque la estranguria había pasado a una iscuria (retención) hacia quince horas, todo presentaba un aspecto fatal, las partes sexuales y sus inmediatas estaban en un estado inflamatorio, y temí la próxima mortificación si no operaba con prontitud como había pensado y lo verifiqué del modo siguiente.

Operación ${ }^{\dagger}$

Situé a la paciente de espaldas sobre una cama, con las extremidades inferiores bien separadas, poniéndole una almohada pequeña en las caderas, para mejor apoyo, y que elevara un poco: introduje el dedo índice de la mano izquierda en la vagina, untado con aceite, habiendo puesto antes una sonda acanalada en la uretra, hasta tocar el cuerpo extraño y afirmarla con el mismo. Satisfecho de esta primera parte, saqué el dedo y ocupé la mano dicha con la sonda; $y$ con la derecha introduje un bisturí delgado y de punta roma, auxiliado con el índice hasta colocarla en principio del canal de la sonda; y después, apoyando el dedo en la espalda del mencionado, hice una incisión que vino a terminar hasta fuera, y retirando los instrumentos, extraje el cálculo (que original se acompaña y representa la lámina) después de media hora de hecha la incisión, porque la enferma trataba de que la naturaleza la concluyera, y no sufrir más dolores, pero por último se decidió: concluida la operación reconocí la vegiga con la sonda de pecho, y no encontré más capacidad en ella, que la que representa el cálculo: le apliqué una cánula lo mejor que se pudo, apoyada en una torunda algo solida untada con cerato, se le aplicaron sus compresas, graduadas, y un vendaje de $T$ de ano para sostener la curación, encargándole quietud, alimento líquido, y un cocimiento de cebada y goma arábiga por uso.

Al día siguiente me recibió la paciente con estas expresiones "bendito sea Dios, Señor, que he sabido lo que es vivir sin dolor". Quité el apósito y no encontré

† La malignidad ha querido rebajar su mérito, atribuyendo violencia a la enferma, e intervención de muchas personas, lo que además de ser falso (pues no hubo más concurrentes que el operante y la madre como es fácil informárselo) en nada disminuiría (aun suponiéndolo) la gloria de haber hecho la operación oportunamente, y quitando a la muerte una víctima que casi estaba bajo su dominio. otra novedad que la paciente no pudo sufrir la cánula, y se la quitó a las dos horas: le hice una inyección de leche tibia y le puse la torunda con el cerato, pero no fue posible conseguir la aplicación de la cánula. Régimen interno los demulcentes.

Con este sencillo método ha seguido desde el día siete de setiembre, sin más novedad que la incontinencia de orina por la omisión de no sufrir la cánula; bien que en esta clase de operaciones por lo regular queda este vicio. El día seis del presente se le ha presentado con regularidad la menstruación, y casi no existe el estado caquéctico: la incontinencia es tan moderada, que procurando la enferma contraer el cuello de la vegiga, está algunas horas sin arrojarla, pero esta acción le molesta porque dice que le cansa: estando en una postura horizontal se deposita la orina en la vegiga en cantidad de un cuarto escaso, y la arroja con conato, lo que prueba que el esfínter de la vegiga no padeció, y con el tiempo hay esperanza de que adquiera su resorte natural ${ }^{\ddagger}$. Guadalajara, diciembre 12 de 1822.

Explicación de la lámina. A. Porción del cálculo, abrasada con el cuello de la vejiga. B. Parte correspondiente al fondo de la misma. C. Vista por su cara anterior. Su peso acabado de extraer era de onza $y$ media escasa. Su figura ha variado por el mucho rose que ha tenido, estaba más áspera, y el cuello más abultado, las porciones que van sueltas le pertenecen (Fig. 4).

\section{Operación de talla según el método lateralizado}

El segundo trabajo se denomina Operación de talla según el método lateralizado, por el Dr. Jecker, escrito por el Dr. Luis Jecker y publicado en el primer número del tomo primero del Periódico de la Academia de Medicina de Mégico en 18367 (Fig. 5). A continuación se transcribe el artículo:

Las enfermedades de las vías urinarias son generalmente comunes en Mégico [sic]; sin embargo, el cálculo o piedra en la vegiga [sic] es bastante raro. Resulta de ahí que las ocasiones de practicar la operación que liberta a los enfermos de este mal no se presentan con frecuencia. Es pues una casualidad bastante extraordinaria que dos operaciones de talla

\footnotetext{
¥ Cuantas medicinas son necesarias las franquea el Profesor de Farmacia D. Juan José de Arezpacochaga gratis.
} 


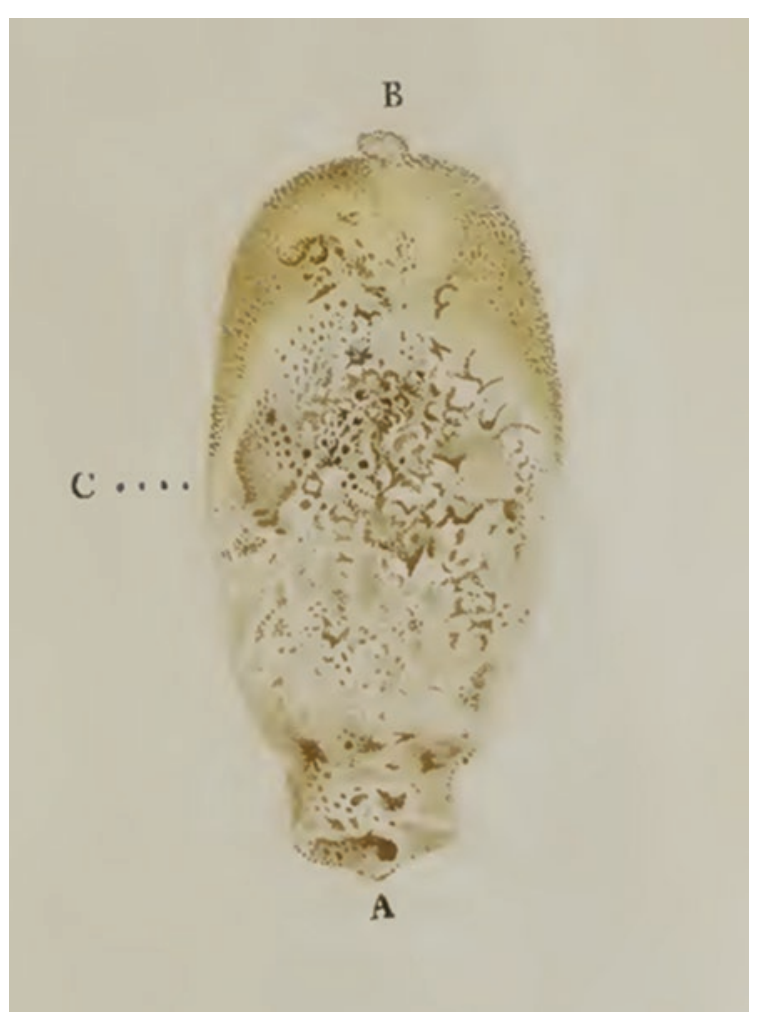

Figura 4. Imagen del cálculo extraído por José Victoriano Guerrero, 1822.

\section{operacion de tarla SEGUN EL METODO} lateralizado, por el Dr. Jeeker.

IAss onfermedades de las vias uri- | parto, dando gritos agudos; ent6nees narias son geberalmente comunes on salian algunas gotas de agua por el M6gico; sin embargo, ol cáleulo 6 pie- meato urinario, las euales so suspendra en la vegiga es bastante raro. dian repentinamente; al mismo tiempo Resulta de ahí que las ocasiones do el pene muy erecido para su edad, se practicar la operacion que liberta á hinchaba se endurecia, se toreia, pa. los enfermos de este mal no se pro- recia entrar en ereceion s la vez que sentan con frecuencia. Es pues una estaba estirado por una contraccion casualidad bastante extraordinaria que convulsiva de los ischio-cavernosos, y dos operaciones do talla bayan sido $\begin{aligned} & \text { convulsiva de los ischio-cavornosos, y } \\ & \text { los testes ostirados fuertomente por }\end{aligned}$ practicadas en seguida con un inter- arriba por la de los eremasteres; al valo do quince a veinte dias : habien- mismo tiempo salia el intestino recto do tenido las dos un resultado favora- cosa de dos $\sigma$ tres pulgadas.

ble, empezarémos por la primera, que $\mathbf{A}$ pesar de estos padecimientos, el segun los datos que tenemos, parece estornago se mantenia bueno, y este ser la primera tambien que se ha ejo- niño teaia salud en ol resto do su cutado en Mŕgico.

Un niño de cinco años padecia ha. cia mas do un año cada vez que ori naba: los dolores faerou constantemente en aumento, $y$ en los áltimos meses que precedieron á la operacion, vod aquí cómo so le puede figurar en el acto de la excrecion de la orina; es decir, cada diez minutos, que era todo el intervalo que tenia libre de esta necesidad. Tan proato como la senta necesidad. Tan probto como la senpenis con una mano, con la otra so ta exploratriz que habia servido en agarraba de los enaguas de su madre, las ocasiones anteriores, despues un. $\checkmark$ do la orilla de un mueblo, la vegi- cateter acanalado do acero, y á pe.

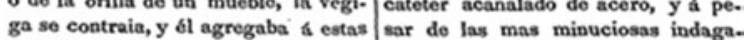
contracciones las do los músculos del ciones, bastante prolongadas, fué proabdomen y del diafragma como on ol ciso abandonar para otro dia la opo-

Figura 5. Artículo Operación de talla según el método lateralizado, por el Dr. Jecker, publicado en el primer número del Periódico de la Academia de Medicina de Mégico, 1836. hayan sido practicadas en seguida con un intervalo de quince a veinte días: habiendo tenido las dos un resultado favorable, empezaremos por la primera, que según los datos que tenemos, parece ser la primera también que se ha ejecutado en Mégico.

Un niño de cinco años padecía hacía más de un año cada vez que orinaba: los dolores fueron constantemente en aumento, $y$ en los últimos meses que precedieron a la operación, ved aquí como se le puede figurar en el acto de la excreción de la orina; es decir, cada diez minutos, que era todo el intervalo que tenía libre de esta necesidad. Tan pronto como la sentía, doblaba el cuerpo cogiendo el penis [sic] con una mano, con la otra se agarraba de las enaguas de su madre, o de la orilla de un mueble, la vegiga se contraía, y él agregaba a estas contracciones las de los músculos del abdomen y del diafragma como en el parto, dando gritos agudos; entonces salían algunas gotas de agua por el meato urinario, las cuales se suspendían repentinamente; al mismo tiempo el pene muy crecido para su edad, se hinchaba, se endurecía, se torcía, parecía entrar en erección, a la vez que estaba estirado por una contracción convulsiva de los ischio-cavernosos, y los testes estirados fuertemente por arriba por la de los cremásteres; al mismo tiempo salía el intestino recto cosa de dos o tres pulgadas.

A pesar de estos padecimientos, el estómago se mantenía bueno, y este niño tenía salud en el resto de su constitución y bastante robustez.

Se sospechó muy breve que estos síntomas anunciaban una piedra en la vejiga; se le sondeó y la piedra fue encontrada y reconocida con bastante facilidad esta primera vez y las siguientes hasta el día que se determinó para practicar la operación.

Este día todo estaba dispuesto para proceder a ella: el enfermito ligado y puesto en la posición debida, se introdujo primeramente la sonda de plata exploratriz que había servido en las ocasiones anteriores, después un catéter acanalado de acero, y a pesar de las más minuciosas indagaciones, bastante prolongadas, fue preciso abandonar para otro día la operación, conformándose el facultativo al precepto formal del arte en esta rara circunstancia.

A los diez días después, el Dr. Jecker, que se había otras veces asegurado más de la presencia del cuerpo extraño, volvió a su primera determinación, y el niño fue operado por él según el método lateralizado y el procedimiento de fray Cosme, en presencia de sus compañeros Sollier, Escobedo, Morón, Blaquière, y varios alumnos del curso de Anatomía. 
La operación fue laboriosísima; desde antes de la primera incisión el niño muy indócil, se movía, gritaba, hacia esfuerzos, que le ocasionaban la salida del recto, pero con tal fuerza, que su reducción era muy dificultosa, y peor su permanencia: fue quizá necesario proceder a esta reducción diez o doce ocasiones antes de poder abrir el cuello de la vegiga. El mismo inconveniente se reprodujo y con más frecuencia todavía al entrar las tenazas; es preciso haberlo presenciado para tener una idea de las dificultades que oponía este accidente a los movimientos del operador y a las circunstancias más importantes de la operación. Tales fueron, que después de muchas tentativas fue preciso por temor de graves accidentes consecutivos, dejar por el momento de continuar la operación, y diferirla hasta algunos días, es lo que se llama hacer la operación en dos tiempos.

El paciente fue desatado, puesto en su cama, las piernas medio encogidas; sometido a una dieta severa, baños largos y renovados en el mismo día, bebidas emolientes y abundantes. A la noche siguiente durmió, ningún accidente grave se manifestó, ningún calosfrío, ningún dolor, solamente el pulso tomó una aceleración que llegó a ciento sesenta y ocho pulsaciones por minuto, y duró varios días en esta misma disposición; por otra parte, el enfermito no teniendo necesidad de hacer esfuerzos para mear; el intestino recto no volvió a salir ni una sola ocasión aun en la segunda operación. Este es el caso del axioma: Sublata causa, tollitur effectus.

A los ocho días de la primera se volvió a la segunda operación; el niño fue colocado como la primera vez: como acabo de decir, el recto no volvió a ponerse en medio y fue fácil agrandar la llaga del cuello de la vegiga, que ya empezaba a cerrarse, y con prontitud sacó el doctor Jecker un cálculo de urato de cal, del tamaño de una nuez, de mediana consistencia, del cual algunos cascos quedaron en la vegiga, pero fueron llevados por medio de algunas lociones de agua de malvas.

Las consecuencias de esta segunda operación fueron las mismas que en la primera. Antes de quince días el niño estaba bueno y sano.

\section{Comentario}

Las dos publicaciones presentadas en este trabajo parecen ser los primeros registros de procedimientos quirúrgicos en niños de México durante el siglo XIX, tal como señala el Dr. Jecker en su trabajo, ya que la revisión de la literatura médica de la época y también la más reciente no registra algún procedimiento quirúrgico en niños. Por ejemplo, en el trabajo Estado actual y progresos de la cirugía en México (desde el año de 1810 en que se inició la Independencia hasta la fecha), escrito por el Dr. Julián Villarreal a nombre de la Academia Nacional de Medicina para el Concurso Científico y Artístico del Centenario en $1911^{8}$, no los menciona; sin embargo, cuando se refiere al Periódico de la Academia de Medicina de Mégico señala que, en la página 33 del número 2 del primer tomo de 1836, hay una observación de talla según el método bilateral después de la litotricia, en un hombre de 52 años, escrito por el Dr. Luis Blaquiere, pero no menciona el trabajo del Dr. Jecker, publicado un mes antes en el mismo Periódico. No obstante, es justo mencionar que, en el libro La cirugía mexicana del siglo XIX, el Dr. Rafael Heliodo Valle enumera el trabajo del Dr. Jecker, pero no menciona que se trata de un niño ni describe el procedimiento 9 .

Poco se conoce sobre José Victoriano Guerrero, pero al igual que otros cirujanos de su época también atendía otros padecimientos, lo que puede confirmarse con unos avisos dirigidos al pueblo de Guadalajara en 1833 sobre un nuevo método curativo para el cólera epidémico ${ }^{10,11}$. Además, es importante señalar que su informe quirúrgico no es de carácter académi$c o$, sino que representa la descripción de una proeza, salvarle la vida a una joven condenada a morir en una época en la que no existían anestésicos ni técnicas de asepsia y antisepsia, acción que el propio Guerrero consideró digna de imprimir como un obsequió al emperador mexicano Agustín I, para celebrar su ascensión al trono.

Con relación al Dr. Luis Jecker existe mayor información. Cabe señalar que en el Periódico de la Academia publicó otros trabajos, tanto médicos como quirúrgicos, entre los que sobresalen Rara conformación accidental de las partes genitourinarias de una muger $^{12}$ y Sobre la neumonía en los niños, lo cual nos muestra la amplitud de su actividad clínica, además de que el trabajo sobre neumonía constituye el primer reporte acerca del tratamiento de dicha enfermedad en los niños de México. El Dr. Jecker, de origen suizo, pero nacionalizado francés (Fig. 6), registró su título en el Protomedicato el 14 de enero de 1831, y aunque su nombre figura en la lista de los cirujanos, está precedido del título de doctor, lo que hace pensar que sus estudios no solo eran en cirugía sino también en medicina ${ }^{14}$. Fue el primer profesor de anatomía en el 


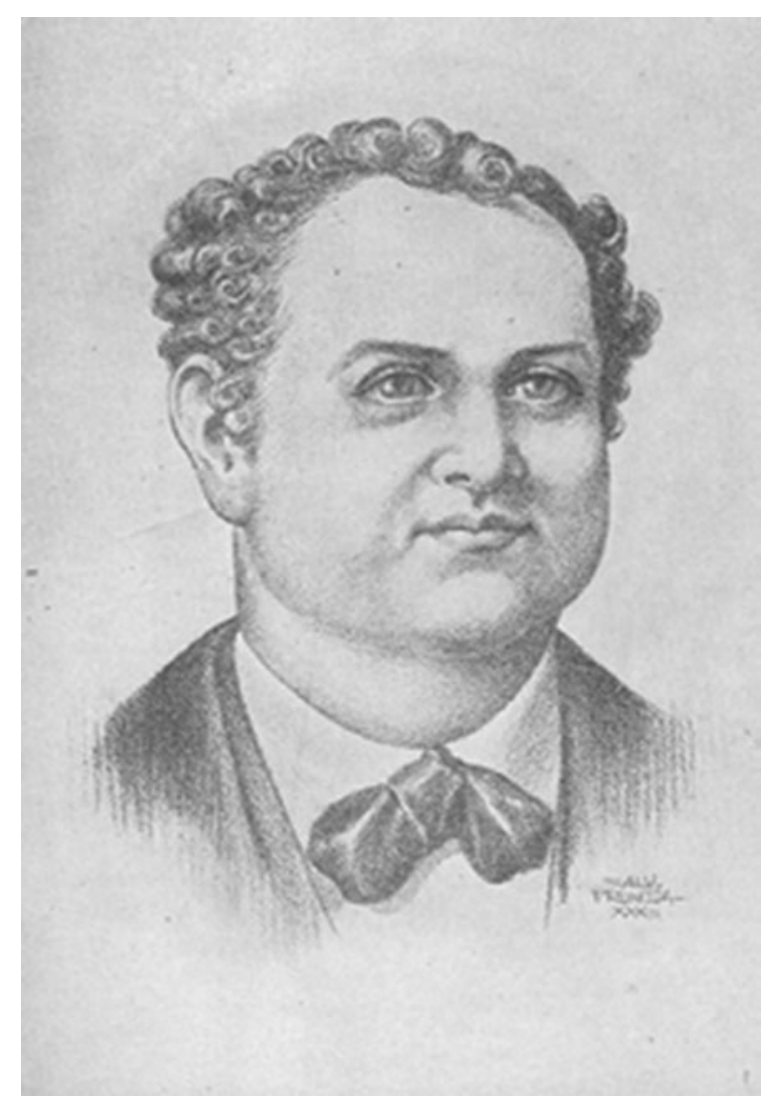

Figura 6. Dr. Luis Jecker, primer profesor de anatomía del Establecimiento de Ciencias Médicas creado en 1833. (Tomado de: El Establecimiento de Ciencias Médicas y sus primeros catedráticos. México: Departamento Autónomo de Prensa y Publicidad, DAAP, 1939.)

Establecimiento de Ciencias Médicas, en sustitución de D. Guillermo Chayne, quien no tomó posesión de su cargo. En su libro Memorias de mis tiempos, Guillermo Prieto, el popular Fidel, dice: «veo a Jecker con su pelo rubio, sus manos rechonchas y acolchonadas, sus ojos azules, su cuerpo obeso, pero listo y con cierto desparpajo de tendero. Pero en las operaciones, se transformaba, su mano era levísima, su bisturí parecía con inteligencia propia, para él era como de cristal el cuerpo humano ${ }^{15}$. De forma semejante se refiere Manuel Payno al Dr. Jecker: «tenía unas grandes manos, con los dedos cortos y gordos, como manos de arriero, pero cuando hacía una operación las manos pulidas de una dama no eran más suaves ni más delicadas. En esa época no se conocían los anestésicos, y los pacientes tenían que sufrir, como verdaderos mártires, una operación 10, $20040 \mathrm{mi}$ nutos. La habilidad y la destreza de Jecker casi suplían al cloroformo, hizo curas y operaciones difíciles en casos, como dicen fríamente los médicos, verdaderamente desesperados. Su fama voló por toda la República; a los ricos les cobraba cuentas enormes; a los pobres les curaba de balde, y a veces les daba algún dinero para las medicinas ${ }^{16}$. Santo en su caridad, en su paciencia y en su amor a los pobres. A este doctor puede llamarse sin exageración el padre de la cirugía en México» ${ }^{15}$. Falleció en París en 1839, a donde se fue a radicar después de salir del país a consecuencia de la Ley de término en que los franceses debían de salir de la República, publicada el 1 de diciembre de $1838^{17}$.

Para concluir, también se debe señalar que Francesco Antommarchi, el médico de Napoleón, encargado de realizar su autopsia y su máscara funeraria, llegó a nuestro país en 1835 y estuvo trabajando como cirujano en México, Durango, Guadalajara y San Luis Potosí, donde realizó numerosas cirugías oftalmológicas, y aunque no existe una descripción de sus operaciones, los Dres. Fernando Serrano y Pascual Agraz dieron fe de su labor quirúrgica y enlistaron sus operaciones en Guadalajara, donde, según su registro, el 13 de octubre de 1835 practicó una talla hipogástrica a un niño de D. Mariano Brambila, y el 17 de ese mismo mes extirpó a otro niño una lipia situada en el ángulo externo del ojo ${ }^{18}$.

\section{Responsabilidades éticas}

Protección de personas y animales. Los autores declaran que para esta investigación no se han realizado experimentos en seres humanos ni en animales.

Confidencialidad de los datos. Los autores declaran que en este artículo no aparecen datos de pacientes.

Derecho a la privacidad y consentimiento informado. Los autores declaran que en este artículo no aparecen datos de pacientes.

\section{Financiamiento}

Sin financiamiento.

\section{Conflicto de intereses}

Sin conflictos de intereses.

\section{Bibliografía}

1. Méndez C. Libro del ejercicio y de sus provechos. Sevilla: Maestro Grigorio de la Torre; 1553.

2. Arias de Benavides P. Secretos de chirurgia. Valladolid: Francisco Fernández de Córdova; 1567.

3. Rodríguez-Paz CA, Carreón-Bringas RM. Algunos aspectos sobre la cirugía pediátrica en el siglo XIX en México. Bol Med Hosp Infant Mex. 2004;61:352-6.

4. Méndez C. Libro del ejercicio corporal y de sus provechos. Estudio, edición y notas de Eduardo Álvarez del Palacio. León: Universidad de León, Secretariado de Publicaciones; 1996. 
5. Chico-Ponce de León F, Goodrich JT, Tutino M, Gordon C. First published record of a neurosurgical procedure on the North American Continent, Mexico City, by Pedro Arias de Benavides, 1561: Secretos de Chirurgia, Valladolid, Spain, 1567. Neurosurgery. 2000;47:216-22.

6. Guerrero JV. Memoria sobre la extracción de un cálculo urinario. Guadalajara: Oficina de don Mariano Rodríguez; 1822.

7. Jecker L. Operación de talla según el método lateralizado, por e Dr. Jecker. Periódico de la Academia de Medicina de Mégico. 1836; 1:9-10.

8. Villarreal J. Estado actual de la cirugía en México. Concurso Científico y Artístico del Centenario. México: Tip. de la viuda de F. Díaz de León, Sucs; 1911.

9. Valle RH. La cirugía mexicana del siglo XIX. México: Tipográfica Sag 1942. p. 91.

10. López JA, Guerrero V. Aviso al pueblo. Método curativo. Guadalajara: Imprenta del Supremo Gobierno; 1833.

11. Guerrero V, López A, Moreno I, Jurado I. Nuevo método curativo y observaciones hechas sobre la cólera epidémica. Guadalajara: Imprenta del C. Urbano Sanromán; 1833.
12. Jecker L. Rara conformación accidental de las partes genitourinarias de una muger. Periódico de la Academia de Medicina de Mégico. 1836; 1:114-6.

13. Jecker L. Sobre la neumonía de los niños. Periódico de la Academia de Medicina de Mégico. 1836;1:345-55.

14. Bandera B. El Dr. don Luis Jecker. En: Centenario de la fundación del Establecimiento de Ciencias Médicas 1833-1933. Contribución de la Academia Nacional de Medicina. México: Departamento Autónomo de Prensa y Publicidad; 1938. p. 55-69.

15. Prieto G (Fidel). Memorias de mis tiempos 1828 a 1840. México: Librería de la Vda. de C. Bouret; 1906. p. 198-9; 300-1.

16. Payno M. Reseña histórica de la invasión en México. México: Imprenta del Gobierno, en el ex-Arzobispado; 1898. p. 17-8.

17. Dublán M, Lozano JM. Legislación mexicana o edición completa de las disposiciones legislativas expedidas desde la Independencia de la república, Tomo III. México: Imprenta del Comercio, a cargo de Dublán y Lozano, Hijos; 1876. p. 566-7.

18. García de Alba GJ. El Dr. Antommarchi. ¿En Guadalajara? Estudios Históricos. 1981;III Época (17):15-23. 